Research Article

\title{
Income Differences between Flexibly and Nonflexibly Employed Persons and Their Deconstruction: An Analysis Based on Data from the 2018 China Mobility Monitor
}

\author{
Xiongying Chen $\left(\mathbb{D},{ }^{1}\right.$ Yu Xie $\mathbb{D}^{2},{ }^{2}$ Keqiang Wu $\mathbb{D},{ }^{2}$ Xin Zhao $\mathbb{D}^{2},{ }^{2}$ BingBing Zhang $\mathbb{D}^{2},{ }^{2}$ \\ Yin Yao ${ }^{(D)}{ }^{2}$ and Xinyu Wang ${ }^{1}$ \\ ${ }^{1}$ Institute of Human Resource Management, Beijing Union University, Beijing 100023, China \\ ${ }^{2}$ School of Management, Beijing Union University, Beijing 100101, China \\ Correspondence should be addressed to Xinyu Wang; wxy006@buu.edu.cn
}

Received 18 November 2021; Accepted 15 December 2021; Published 30 December 2021

Academic Editor: Daqing Gong

Copyright (c) 2021 Xiongying Chen et al. This is an open access article distributed under the Creative Commons Attribution License, which permits unrestricted use, distribution, and reproduction in any medium, provided the original work is properly cited.

\begin{abstract}
The article analyzed the income differences between flexibly and nonflexibly employed persons based on the 2018 China Mobile Population Dynamics Monitoring Data, using OLS methods, propensity score matching (PSM), and Oaxaca-Blinder decomposition. The results show that the income of flexibly employed persons is $11.9 \%-23.6 \%$ higher than that of nonflexibly employed persons, with differences in individual endowment characteristics explaining $53.9 \%$ of the income difference and differences in coefficients of nonmarket factors explaining $45.7 \%$ of the income difference. The degree of income difference between the two groups in different industries varies; except for the primary industry, the secondary and tertiary industries all show higher income for flexibly employed persons than for nonflexibly employed persons. The difference in income between the two groups was as high as $25 \%$ or more in the sectors of "rental and business services," "education," and "culture, sports, and entertainment." The high ratio of employers and self-employed workers in flexible employment and the fact that the average number of hours worked per week is 12.6 hours higher for flexible workers than for nonflexible workers are important factors contributing to the difference in earnings between these two groups. Clarifying the extent of the current income disparity between flexible and nonflexible employment groups and its sources, and formulating and adjusting relevant policies and measures in a timely manner are conducive to creating a fair and equitable labour market environment and promoting the healthy development of flexible employment under the new circumstances.
\end{abstract}

\section{Introduction}

In July 2020, the General Office of the State Council issued the Opinions of the General Office of the State Council on Supporting Flexible Employment through Multiple Channels, which pointed out that "flexible and diversified employment methods such as self-employment, part-time employment, and new employment forms are important ways for workers to increase their income and play an important role in widening new employment channels and fostering new momentum for development." It is requested that "flexible employment is supported as an important measure to stabilize employment and preserve employment for the population," and that multiple measures be taken to promote flexible employment [1]. According to a study by the China Academy of Labour and Social Sciences, about 200 million people are currently engaged in flexible employment in China, and the new economy has given rise to many new forms of employment that have absorbed a large number of employed people. Taking employment in sharing economy platform enterprises as an example, the number of participants in the sharing economy will be about 830 million in 2020 , including about 84 million service providers, an increase of about $7.7 \%$ year-on-year; the number of employees in platform enterprises will be about 6.31 million, an increase of about $1.3 \%$ year-on-year [2]. Compared to the traditional 
mainstream employment under the modern factory system, flexible employment is a general term for various forms of employment that differ in terms of working hours, income remuneration, workplace, insurance benefits, and labour relations (Yin, 2012) [3]. Flexible employment has flourished in the labour market because it has lower entry barriers and flexible entry and exit mechanisms compared to nonflexible employment, and can adapt to a wider range of economic structures and rapidly changing economic situations, allowing enterprises to save costs and employees to have freer working arrangements or higher incomes (Liu, 2009) [4]. The sudden outbreak of COVID-19 combined with China's downward pressure on economic operation has a considerable impact on the labour market, the new flexible employment relying on the Internet platform has played an important role in promoting and stabilizing employment, the structure of flexible employment has gradually changed from the mainly low-end manufacturing and service industries to the high-end in the past, and the employment situation of employees has also improved to some extent. From the perspective of the development of flexible employment in China, flexible employment emerged and developed in the context of the transformation of the system that started in the 1970s and 1980s, which led to the manifestation of hidden unemployment, the change in employment structure caused by the upgrading of industrial structure, the waxing and waning of jobs due to technological progress, and the huge pressure on employment caused by the transfer of rural labour. Since the emergence of flexible employment, a large proportion of employees has faced problems such as low income levels, long working hours, high labour intensity, and low levels of protection of rights and interests due to its low barriers to entry, irregular development, and weak coverage of relevant legal regulations (Mu et al. 2016 [5]; Hu and Shao, 2020 [6]), making the differences in wages and income between flexible and nonflexible employees, protection of rights and interests, and other issues as a matter of great concern to all sectors. In the current context of deeper segmentation of the labour market and the persistence of market discrimination (Zhang et al., 2018 [7]; Zhang, 2019 [8]), the issue of income differentials deserves continued in-depth study.

\section{Literature Review}

On the issue of income differentials between flexibly and inflexibly employed people, on the one hand, scholars have given explanations from a theoretical perspective. Human capital theory suggests that the fundamental cause of income differences lies in differences in the productivity of their labour (Schultz and Theodore, 1960 [9]; Wang, Cai et al., 2008 [10]), and that flexibly employed people can earn high incomes by improving their human capital. Market discrimination theory suggests that some workers are treated unfairly in terms of employment, job selection, promotion, remuneration, and training due to noneconomic personal characteristics, such as employers often having a negative perception of those who have worked in flexible employment, leading to differences in earnings between flexible and nonflexible workers (Blinder, 1973 [11]; Mao, 2005 [12]; Li and Zhao, 2012 [13]; Hou, 2019 [14]). On the other hand, scholars have also conducted relevant empirical analyses. Focusing on formal and informal employment, scholars at home and abroad have conducted empirical studies from different perspectives and using different methods. From relevant studies abroad, Chen and Hamori (2013) [15] estimated the difference in hourly earnings between formal and informal employment in urban China and found that formal and informal employment characteristics have a greater impact on the hourly earnings gap than discrimination in the labour market. Using HILDA data analysis, Green and Leeves (2013) [16] found that flexibly employed workers will face more unemployment and increased job insecurity; however, these negative outcomes are gradually mitigated by the extension of their job tenure. de Lange et al. (2014) [17] investigated the impact of flexible employment when entering the Dutch labour market from 1986 to 2008 on the early careers of Dutch students, finding that being in flexible employment when they entered the Dutch labour market would increase the probability of repeated flexible employment and unemployment in the early stages of their careers, along with relatively little career status development and income growth. Fátima and Maria (2017) [18]explored the differences in pay for Portuguese workers in contractual arrangements, with empirical results showing that workers in formal employment receive more vacation bonuses, health insurance, or food subsidies, for example, compared to workers in informal employment, pointing out that the exploitation of informal workers in the labour market is evident. From the research of domestic scholars, relevant studies focus on two aspects: one is about the degree of difference between formal and informal employment in terms of wage income, and the basic result is that formal employment has higher wage income than informal employment. By using CHNS data from 1997 to 2006 and the 2014 China Labour Force Dynamics Survey (CLDS) data, respectively, Qu (2011) [19] and Zhang et al. (2018) [7] both argued that the average salary of formal employment is higher than that of informal employment, and the wage gap between the two shows a gradual decrease. The second is about the causes of wage income differences between formal and informal employment, which mainly involve individual endowment factors such as workers' human capital and social capital, as well as nonmarket factors such as gender discrimination. Chang and Wang (2010) [20] found through their survey that the income gap between formal and informal employment mainly stems from the advantages of formal employment in terms of human capital allocation. Wei and Yu (2012) [21] used 2009 CHNS data to conduct empirical study; the results show that the wage differential between formal and informal employment is mainly caused by the wage differential at the middle and low end, and the causes of the wage differential at the low end are mainly nonmarket factors such as discrimination, and the high end is mainly due to differences in individual endowments such as education and experience. Based on CGSS data, Ding (2017) [22] found that gender discrimination is more pronounced in informal employment and becomes more 
serious as the wage quantile increases. Wang (2017) [23] conducted an empirical study on the wage difference between formal and informal employment in urban China from 1989 to 2011, and the results showed that the wage gap between the two types of employment groups is asymmetric and the difference in characteristics explained by individual endowments is increasing, while the difference in coefficients explained by nonmarket factors has been declining, reflecting that China's labour market has generally become more fair and better, and the wage determination mechanism has become more market-oriented.

As can be seen from the above, most of the existing studies are on the differences between the wages of people in formal and informal employment, while the "flexible employment" discussed in this study is not the same as "informal employment." According to a study conducted by a group from the Institute of Labour Science of the Ministry of Labour and Social Security, flexible employment includes the following six types: (1) subsistence social labour organizations, including informal labour organizations and labour and employment service enterprises; (2) other informal sector employment, including urban self-employed workers and small and medium-sized private enterprises; (3) flexible employment in the formal sector, including noncore employees, part-time workers, seasonal workers, short-term contract workers, temporary workers, apprentices, trainees, external workers, etc.; (4) labour dispatch workers; (5) casual labour; and (6) freelance workers, mainly referring to flexible employment in the cultural field, social intermediary services, and high-tech fields [24]. At present, empirical studies on the income difference between flexible and nonflexible employment are relatively rare; at this stage, flexible employment has changed somewhat compared to the previous one in terms of scale, structure, income benefits of the employees, etc. The survey data used in some studies are old and cannot fully reflect the current level of income difference between flexible and nonflexible employment. The Fifth Plenary Session of the 19th Central Committee clearly stated that one of the main objectives of China's economic and social development during the 14th Five-Year Plan period is to achieve fuller and higher quality employment, and to significantly improve the income distribution structure. Faced with the changes in the employment structure due to the expansion of flexible employment and the emergence of new flexible employment methods, what are the new changes in the income levels of flexible and nonflexible workers? What are the main areas of income disparity between the two? How have the causes of income disparities changed? All these questions need to be answered clearly. It is necessary to remeasure the income difference between flexible and nonflexible workers at this stage, to explore the reasons and mechanisms behind the difference, and to provide a basis for policy formulation to bridge the income difference between different modes of employment. To this end, based on the current employment situation and general conditions, this study intends to focus on the impact of different modes of employment on the income of workers by analyzing the 2018 data on the monitoring of mobility dynamics, revealing the new situation of the difference in income levels between flexibly and nonflexibly employed workers, and providing a detailed analysis of the income differences between the two modes of employment and their causes.

\section{Research Methods}

In this study, OLS regression analysis and Propensity Score Matching (PSM) were used to estimate the difference in earnings between flexible and nonflexible workers. In the OLS approach, the explanatory variable is the logarithm of the monthly income of the mobile population, "flexible versus nonflexible employment" is a binary dummy explanatory variable, and its coefficient estimates reflect the income difference between flexible and nonflexible workers, with some control variables. To obtain optimal linear unbiased estimates, it is necessary to satisfy the requirement that a person's employment in flexible or nonflexible employment is completely randomly determined, but if your employment is self-selected, then the OLS approach will produce selectivity bias.

In order to avoid the problem of selection bias and to obtain accurate results, this study will attempt to estimate the difference between the income of flexibly and inflexibly employed persons using the PSM method. The relationship between the two methods can be explained as follows: let Y represent the income of the mobile population; $D$ be a binary dummy variable, where $D=1$ represents "flexible employment" and $D=0$ represents "nonflexible employment"; then $Y_{1}$ represents the income of the flexibly employed and $Y_{0}$ represents the income of the nonflexibly employed; and let $X$ represent a set of control variables. The result estimated by the OLS method is actually $E\left(Y_{1} / X, D=1\right)-E\left(Y_{0} / X, D=0\right)$, and this equation can be expanded as

$$
E\left(\frac{Y_{1}}{X}, D=1\right)-E\left(\frac{Y_{0}}{X}, D=0\right)=\left[E\left(\frac{Y 1}{X}, D=1\right)-E\left(\frac{Y_{0}}{X}, D=1\right)\right]+\left[E\left(\frac{Y}{X}, D=1\right)-E\left(\frac{Y_{0}}{X}, D=0\right)\right]
$$

\section{(ATT) (Selectivity Bias)}

The subitem ATT is the difference between the actual earnings of those in "flexible employment" and what they would have earned if they were in "nonflexible employment." It reflects the difference between the actual earnings of those in flexible and nonflexible employment, and is the unbiased estimate that this paper seeks to obtain. 
The "selectivity bias" is the difference between what a "flexibly employed" person would have earned if he or she had been in nonflexible employment and what those who were actually in "non-flexible employment" would have earned, i.e., the difference between $E\left(Y_{0} / X, D=1\right)$ and $E\left(Y_{0} /\right.$ $X, D=0)$.

Equation (1) illustrates that the income differentials estimated by OLS methods include both ATT and selectivity bias, and that selection bias biases the results of OLS regressions. In practice, only the income $E\left(Y_{1} / X, D=1\right)$ of people in flexible employment can be observed, and the income $E\left(Y_{0} / X, D=1\right)$ of those people had they been in nonflexible employment at the same time cannot be observed to obtain an accurate value of ATT. Therefore, this study uses the PSM to estimate this counterfactual.

The steps in using the propensity score matching method are as follows: (1) select the control variable $X$, including relevant variables affecting $Y_{0}, Y_{1}$, and $D$ where possible; (2) estimate the propensity score, generally using the logit regression to estimate the probability of each practitioner choosing flexible or nonflexible employment; (3) conduct propensity score matching if the propensity score is estimated more accurately, so that $X$ is distributed more evenly in the matched treatment and control groups after matching; and (4) calculate the ATT based on the matched sample (Bryson and Purdon, 2002 [25]; Caliendo and Sabine, 2005 [26]).

To further illustrate whether the income difference between flexible and nonflexible employees comes from the difference in the value of variables represented by $X$ (i.e., difference in human capital) or from the coefficient difference (i.e., market discrimination, etc.), based on the human capital theory and market discrimination theory mentioned above, this study assumes that the income of China's floating population is not only affected by its human capital level but also limited by labour market discrimination, and tries to analyze the mechanism of the income difference between the two forms of employment by the income difference decomposition method.

The income differential decomposition method that has been used in most studies is the Oaxaca-Blinder income differential decomposition method proposed by Oaxaca and Blinder almost at the same time in 1973. This method analyzes the mechanism of income differences between the two groups by decomposing the source of income differences into "characteristic differences" and "coefficient differences." Among them, "characteristic difference" represents the income difference caused by personal characteristics, and "coefficient difference" represents the income gap that cannot be explained by personal characteristics and is generally explained by nonmarket factors. The OaxacaBlinder income differential decomposition method can be specified as follows.

$$
\ln W_{f}-\ln W_{i}=\left[X_{f}-X_{i}\right] \beta_{i}+X_{f}\left[\beta_{f}-\beta_{i}\right] .
$$

In Equation (2), flexible employment and inflexible employment are denoted by the subscripts $f$ and $i$, respectively. $\ln W_{f}$ represents the logarithm of the monthly income of flexibly employed people, while $\ln W_{i}$ represents the logarithm of the monthly income of inflexibly employed people. The mean nonindividual characteristic vectors of the sample in the two employment groups are $X_{f}$ and $X_{i}$, respectively, and the corresponding regression coefficient vectors are $\beta_{f}$ and $\beta_{i}$, with $\left[X_{f}-X_{i}\right] \beta_{i}$ representing the "characteristic differences" and $X_{f}\left[\beta_{f}-\beta_{i}\right]$ representing the "coefficient differences" due to nonmarket factors (Guo et al., 2011) [27].

\section{Data Presentation and Descriptive Statistics}

The primary data source for this study is the National Health Commission's 2018 Mobile Population Dynamics Monitoring Survey data. The survey covers the mobile population in 31 provinces (including autonomous regions and municipalities) and the Xinjiang Production and Construction Corps, who are aged 15 years or older, with a nonlocal household registration and have lived in the inflow area for more than one month, with a total sample size of 152,000 . The dataset satisfies the large sample size requirement of the PSM method and provides a relatively rich set of variables, including age, gender, education level, and working area for each sample. Therefore, the PSM method is used to match the characteristics variables of the sample and estimate the difference in income between the mobile population engaged in flexible and nonflexible employment under different demographic characteristics.

In this study, the age of the study population is limited to 16-60 years, so as to ensure that the income of nonflexibly employed workers comes from work rather than retirement wages. Samples without income statistics are excluded as well. The final valid sample size of this study is approximately 125,000 . Based on the type of employment status of workers in the data, this study defines flexible and nonflexible employed persons, with flexible employed persons including employees with no regular employer (odd jobs, casual work, etc.), employers, self-employed workers, and others. Nonflexible workers mainly include employees with a regular employer. The sample distribution is shown in Table 1.

As can be seen from the last two columns of Table 1, there is little difference between flexible and nonflexible workers in terms of gender, marital status, number of years of current mobility, and proportion of educational attainment, but there is a greater difference in the proportions of age, region of work, and industry of work.

In terms of gender, the proportion of men and women in flexible and nonflexible employment is equal, with a slightly higher proportion of men than women. In terms of age, the proportions of flexible and nonflexible workers are similarly distributed, with the majority of the working population between the ages of 31 and 50, and fewer in the labour force aged 30 and below or older than 50. The proportion of flexibly and nonflexibly employed workers aged $31-50$ is close. The proportion of flexible and nonflexible employees aged 30 and below and over 50 is different. The proportion of workers aged 30 and below in flexible employment is significantly lower than the proportion of those engaged in 
TABLE 1: Sample distribution.

\begin{tabular}{|c|c|c|c|}
\hline Variable & Factor & $\begin{array}{l}\text { Percentage of flexibly } \\
\text { employed persons }\end{array}$ & $\begin{array}{c}\text { Percentage of nonflexibly employed } \\
\text { persons }\end{array}$ \\
\hline \multirow{2}{*}{ Gender } & Male & 59.3 & 53.9 \\
\hline & Female & 40.7 & 46.1 \\
\hline \multirow{3}{*}{ Age } & 30 years and below & 22.3 & 42.9 \\
\hline & $31-50$ years & 67.4 & 51.3 \\
\hline & Over 50 years & 10.3 & 5.8 \\
\hline \multirow{4}{*}{ Region of work } & East & 37.5 & 55.8 \\
\hline & Central & 23.0 & 15.8 \\
\hline & West & 33.7 & 23.1 \\
\hline & Northeast & 5.9 & 5.3 \\
\hline \multirow{2}{*}{ Marital status } & Single & 20.7 & 18.5 \\
\hline & Nonsingle & 79.3 & 81.5 \\
\hline \multirow{2}{*}{ Years of current mobility } & 10 years or less & 77.7 & 77.8 \\
\hline & More than 10 years & 22.3 & 22.2 \\
\hline \multirow{3}{*}{ Educational attainment } & Below lower secondary & 13.5 & 14.2 \\
\hline & Lower secondary and post-secondary & 65.9 & 65.2 \\
\hline & College and above & 20.7 & 20.6 \\
\hline \multirow{3}{*}{ Industry of work } & Primary industry & 3.4 & 1.0 \\
\hline & Secondary industry & 11.5 & 38.3 \\
\hline & Tertiary sector & 85.2 & 60.6 \\
\hline
\end{tabular}

nonflexible employment, while the proportion of flexibly employed workers aged over 50 is higher than that of nonflexibly employed workers in that age group. In terms of regional distribution of where workers work, the number of workers in flexible and nonflexible employment groups is equal in the eastern and western regions, with a slightly lower proportion in the central region and a significantly lower proportion in the northeast region. Meanwhile, the proportion of flexibly employed workers in the eastern region is significantly lower than that of nonflexibly employed workers, the proportion of flexibly employed workers in the central and western regions is slightly higher than that of nonflexibly employed workers, and the proportion of the two employment groups in the northeastern region is the same. In terms of marital status, the ratio of single and nonsingle workers is both close to $2: 8$ in two employment groups, and the vast majority of workers are nonsingle. From the perspective of the length of mobility, the proportion of those who have been in flexible employment or nonflexible employment for 10 years or less is close to $80 \%$, accounting for the majority of the sample. In terms of educational attainment, the proportion of flexibly and nonflexibly employed workers with education at the tertiary level and above is only about $20 \%$, reflecting the low level of human capital of the floating population in this survey. In terms of the distribution of industries to which workers belong, the tertiary industry has the most flexible workers compared to the primary and secondary industries, accounting for more than $85 \%$ of the total. The proportion of flexibly employed workers is higher than that of nonflexibly employed workers in the tertiary sector and lower in the secondary sector, while the overall proportion of mobile population employed in the primary sector is lower, at less than $5 \%$.

This study provides statistics on the number and proportion of flexible and nonflexible workers in the valid sample, as well as their average monthly income levels (see Table 2). Table 2 shows that flexible workers accounted for $44.6 \%$ of the overall population, slightly lower than the proportion of nonflexible workers (55.4\%). The average monthly income of nonflexible workers was RMB 4,651.5, which was lower than the overall salary of flexible workers (RMB 5,361.9). In addition, the average monthly income of employers and self-employed workers is higher than that of nonflexible workers, with employers having the highest average monthly income of RMB 9,122.4.

At the same time, this study provides statistics on the differences in the distribution of the average monthly income of flexible and nonflexible workers in different quartiles (see Figure 1). It can be seen from Figure 1 that when income levels are below the 0.3 quantile, the income of flexible employed persons is lower than that of nonflexible employed persons. The income of the two employment groups is basically equal between the 0.3 and 0.5 quantiles, and when income levels are above the 0.5 quantile, the income of flexibly employed persons is higher than that of nonflexibly employed persons, and this difference in income levels after the 0.7 quantile widens rapidly as the quantile rises. This indicates that flexible employment is polarized, and the lower end of the scale coexists with the upper end. Meanwhile, it also reflects the emergence of new employment patterns derived from the new business model, with the overall shift towards the upper end of the scale and the new flexible employment taking on new life.

\section{Estimates of Income Differences between Flexible and Nonflexible Workers}

5.1. Estimation Results of the OLS. Looking first at the difference in income between flexible and nonflexible workers as estimated using the OLS method, the regression equation is as follows: 
TABLE 2: Distribution of the sample of flexibly and nonflexibly employed persons.

\begin{tabular}{|c|c|c|c|c|}
\hline \multirow{2}{*}{$\begin{array}{l}\text { Employment status } \\
\text { Nonflexible employment }\end{array}$} & \multicolumn{2}{|c|}{ Number of persons } & Percentage & Average monthly income (\$) \\
\hline & With regular employer & 69052 & 55.4 & 4651.5 \\
\hline \multirow{5}{*}{ Flexible employment } & No fixed employer & 8238 & 6.6 & 3832.7 \\
\hline & Employer & 9128 & 7.3 & 9122.4 \\
\hline & Self-employed & 37117 & 29.8 & 4814.9 \\
\hline & Other & 1045 & 0.8 & 3997.0 \\
\hline & Overall & 55528 & 44.6 & 5361.9 \\
\hline
\end{tabular}

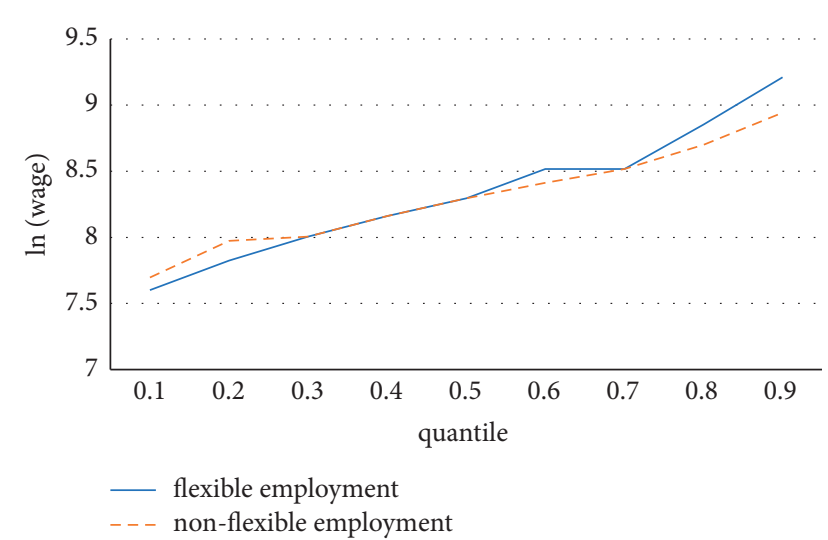

FIGURE 1: Distribution of logarithmic monthly income quartiles of flexible and nonflexible workers.

$$
\ln (\text { income })=\beta_{0}+\beta_{1} x_{1}+\beta_{2} x_{2}+\mu,
$$

where $\ln$ (income) represents the logarithm of the monthly income of the mobile population, where income includes wages, bonuses, cash benefits, subsidies, income in kind, and is net of five insurances and taxes, and foreign currency wages are converted to RMB; $x_{1}, x_{2}$ and other symbols in equation (3) are described in Table 3.

As can be seen in Table 4, the average monthly income of flexibly employed persons among the mobile population was $13.1 \%$ higher than that of nonflexibly employed persons in 2018, controlling for factors such as gender and age, and was significant at the $1 \%$ level of significance.

\subsection{Estimation Results of the Propensity Score Matching Method}

5.2.1. Probability of a Worker Being in Flexible Employment (Propensity Score). First, a binary logit model was used to estimate the probability of each worker being in flexible employment, with the following regression equation.

$$
F=\beta_{0}+\beta_{1} X+\mu,
$$

where $F$ is a binary dummy variable ( $F=1$ for flexible employment and $F=0$ for inflexible employment); $X$ represents a set of independent variables, $X$ contains variables that can affect both the mode of employment of the worker and his earnings and they are determined before the worker determines the mode of employment and are not affected by the mode of employment. Here $X$ includes the same control variables as in the OLS model.
The results of the logit model data show that: the probability of engaging in flexible employment is higher for men than for women; the probability of engaging in flexible employment is significantly lower for mobile people under the age of 30 than for those aged over 50; the probability of engaging in flexible employment is higher in the central and western regions, while the probability of engaging in flexible employment is the lowest for mobile people in the eastern region; the probability of engaging in flexible employment is significantly lower for single mobile people than for nonsingle mobile people. Mobile people with less than 10 years of current mobility are less likely to be in flexible employment than those who have been mobile for more than 10 years. The proportion of those with tertiary education and above engaging in flexible employment is significantly lower than those with other education levels; taking the tertiary industry as the benchmark, the probability of flexible employment is higher in the primary industry and the lowest in the secondary industry.

5.2.2. Equilibrium Tests and Overlaid Hypotheses. (1) Balance Test. The conditional independence assumption $Y_{0} \perp D /$ $P(A)$ must be satisfied when estimating ATT using the propensity score matching method, and it is valid subject to the equilibrium condition $D \perp X / P(X)$. Often, it is difficult to test the conditional independence assumption in practical applications, and what can be performed is a test of equilibrium.

The equilibrium condition is that the decision to be flexibly or nonflexibly employed is made randomly by individuals with the same propensity score. It is also necessary to test whether flexibly employed and nonflexibly employed individuals with the same propensity score have the same individual characteristics $X$, i.e., the means of the individual variables represented by $X$ in the matched experimental group are closer to the corresponding means in the control group. The following are the results of the tests using the different tests (see Tables 5 and 6).

From Table 5, we can obtain that each variable shows significant differences in means before matching, but no significant differences after matching; $t$-tests and $p$ values show that the control variables are well balanced after matching and the $p$ value for each variable becomes very large after matching, so we cannot reject the null hypothesis that the variables are equally distributed, i.e., there are no significant differences in the personal characteristics of flexibly employed and nonflexibly employed people after matching (Test of Method 1 results). Furthermore, the mean 
TABLE 3: Definition and description of formula symbols.

\begin{tabular}{|c|c|}
\hline $\begin{array}{l}\text { Formula } \\
\text { symbols }\end{array}$ & Definition \\
\hline $\ln$ (income) & The logarithm of the monthly income of the mobile population \\
\hline$x_{1}$ & A binary dummy variable ( $x_{1}=1$ refers to flexible employment; $x_{1}=0$ refers to nonflexible employment) \\
\hline$x_{2}$ & $\begin{array}{c}\text { Control variables (gender, age, marital status, education level, number of years of this mobility, area of work, and } \\
\text { industry) }\end{array}$ \\
\hline$\beta_{0}$ & The coefficient of the constant term \\
\hline$\beta_{1}$ & $\begin{array}{c}\text { The percentage change in monthly earnings caused by being in flexible employment compared to being in nonflexible } \\
\text { employment }\end{array}$ \\
\hline$\beta_{2}$ & The corresponding coefficient vector \\
\hline$\mu$ & The error term \\
\hline
\end{tabular}

TABLE 4: Differences in income between flexible and nonflexible workers - OLS regression results.

\begin{tabular}{lccc}
\hline Variables & Coefficients & Statistics & Values \\
\hline \multirow{2}{*}{ Flexible employment } & \multirow{2}{*}{$0.131^{* * *}$} & $R$-squared & 0.198 \\
& & Adj $R$-squared & 0.198 \\
Other control variables & \multirow{2}{*}{ Omitted } & $p$ value & 0.000 \\
& & Sample size & 124580 \\
\hline
\end{tabular}

Note. ${ }^{* * *}$ indicates significant at the $1 \%$ level of significance. Control variables specifically include gender, age, marital status, education level, number of years in the current job, area of work, and industry.

deviation of each variable decreases by more than $90 \%$ after matching (test result of Method 2). A 3\% or 5\% reduction in the standard deviation after matching compared to the standard deviation before matching is sufficient; the greater the reduction, the better the quality of the match.

As shown in Table 6, the pre-matching Pseudo $R^{2}$ values are large and the $p$ values are small, but after matching the Pseudo $R^{2}$ values become smaller and the $p$ values become large and close to 1 . So for the overall variables, the prematching distributions are different and the post-matching distributions are not significantly different.

All tests showed that the series of control variables were well matched and the sample data passed the balance test.

(2) Overlapping Assumptions. This assumption implies that for any possible value of $X$, there is $0<P(D=1 / X)<1$, making it possible to match the two subsamples, the experimental and control groups, to overlap and for both to have the same part of the range of propensity score values. The one-to-one matching method is the simplest matching method in PSM and is used to estimate the matching effect. According to Table 7, which gives the matching of the samples, it can be seen that all the samples in the data were matched and the final sample size was 124,580 .

5.3. Estimating ATT. There are several common matching methods for ATT estimation, such as k-nearest neighbour matching, caliper matching, caliper and radius matching, kernel matching, local linear regression matching, and martingale matching, each of which has its own advantages and disadvantages, and there is no clear conclusion as to which matching method and parameter value to use, which should be chosen for the specific problem. Therefore, this study used several sets of matching methods and parameter values to estimate income differences and compare the estimated estimated results, and the estimated ATTs using different matching methods and parameter values are shown in Table 8.

As we can see in Table 8, when different matching methods and different matching parameters are used, the matching results show that the income of flexibly employed persons in the sample is $11.9 \%-23.6 \%$ higher than that of nonflexibly employed persons, indicating that the difference in income between the two groups calculated with the propensity score matching method has some deviation from that calculated with the OLS method (13.1\%), proving that there is a selection bias in whether the mobile population is engaged in flexible employment or not, but in general the difference between the results estimated by these two methods is small and the sample self-selection problem is not serious.

\section{Analysis of the Sources of Income Differences between Flexible and Nonflexible Workers}

6.1. Oaxaca-Blinder Income Variance Decomposition. In this study, the Oaxaca-Blinder income difference decomposition method was used to decompose the mean value of income difference between flexible and nonflexible employed persons. The decomposition variables were five individual characteristic variables such as gender, age, marital status, education level, and years of current mobility, and the results of the decomposition are shown in Table 9. The results show that the mean difference in log monthly income between the two forms of employment is 0.0254 , and that the income of flexibly employed persons is higher than that of nonflexibly employed persons, which is consistent with the previous estimation results; the value of 0.0137 of the difference is explained by the individual characteristics of the practitioners, which is the difference in characteristics, accounting for $53.9 \%$. Apart from this, the part that cannot be explained by individual characteristics is the coefficient difference, which is mainly caused by nonmarket factors, such as labour market segmentation, gender discrimination, and household registration barriers. The coefficient difference accounts for $45.7 \%$ of the income difference between these two employment groups, which is slightly lower than the characteristic difference. It can be seen that individual 
TABLe 5: Test results for equilibrium conditions, Methods 1 and Method 2.

\begin{tabular}{|c|c|c|c|c|c|c|c|}
\hline \multirow[b]{2}{*}{ Variables } & \multirow[b]{2}{*}{ Sample } & \multicolumn{2}{|c|}{ Variable mean } & \multirow[b]{2}{*}{$\%$ bias } & \multirow{2}{*}{$\begin{array}{c}\text { \% Reduce | } \\
\text { bias } \mid\end{array}$} & \multicolumn{2}{|c|}{$t$-test } \\
\hline & & $\begin{array}{c}\text { Experimental } \\
\text { group }\end{array}$ & $\begin{array}{l}\text { Control } \\
\text { group }\end{array}$ & & & $\mathrm{t}$ & $\begin{array}{c}p>1 \\
t \mid\end{array}$ \\
\hline \multicolumn{8}{|l|}{ Age } \\
\hline \multirow[t]{2}{*}{ Gender } & $\begin{array}{l}\text { Before } \\
\text { matching }\end{array}$ & 0.593 & 0.539 & 10.900 & & 19.120 & 0.000 \\
\hline & After matching & 0.593 & 0.593 & 0.000 & 100.000 & -0.010 & 0.995 \\
\hline \multirow[t]{2}{*}{30 years and under } & $\begin{array}{l}\text { Before } \\
\text { matching }\end{array}$ & 0.223 & 0.429 & -45.200 & & -78.530 & 0.000 \\
\hline & After matching & 0.223 & 0.223 & 0.000 & 100.000 & -0.010 & 0.994 \\
\hline \multirow[t]{2}{*}{$31-50$ years } & $\begin{array}{l}\text { Before } \\
\text { matching }\end{array}$ & 0.674 & 0.513 & 33.200 & & 57.960 & 0.000 \\
\hline & After matching & 0.674 & 0.674 & 0.000 & 99.900 & -0.030 & 0.974 \\
\hline \multirow{2}{*}{$50+$ years } & $\begin{array}{l}\text { Before } \\
\text { matching }\end{array}$ & 0.104 & 0.058 & 16.900 & & 30.140 & 0.000 \\
\hline & After matching & 0.104 & 0.103 & 0.000 & 99.800 & 0.060 & 0.953 \\
\hline \multicolumn{8}{|l|}{ Area of work } \\
\hline \multirow[t]{2}{*}{ East } & $\begin{array}{l}\text { Before } \\
\text { matching }\end{array}$ & 0.375 & 0.558 & -37.300 & & -65.290 & 0.000 \\
\hline & After matching & 0.375 & 0.375 & 0.000 & 100.000 & -0.020 & 0.985 \\
\hline \multirow[t]{2}{*}{ Central } & $\begin{array}{l}\text { Before } \\
\text { matching }\end{array}$ & 0.230 & 0.158 & 18.300 & & 32.390 & 0.000 \\
\hline & After matching & 0.230 & 0.230 & 0.000 & 100.000 & -0.010 & 0.994 \\
\hline \multirow[t]{2}{*}{ West } & $\begin{array}{c}\text { Before } \\
\text { matching }\end{array}$ & 0.337 & 0.231 & 23.600 & & 41.590 & 0.000 \\
\hline & After matching & 0.337 & 0.337 & 0.000 & 99.900 & 0.020 & 0.985 \\
\hline \multirow[t]{2}{*}{ North east } & $\begin{array}{c}\text { Before } \\
\text { matching }\end{array}$ & 0.059 & 0.053 & 2.300 & & 3.960 & 0.000 \\
\hline & After matching & 0.059 & 0.059 & 0.000 & 99.700 & 0.010 & 0.990 \\
\hline \multicolumn{8}{|l|}{ Marital status } \\
\hline \multirow[t]{2}{*}{ Single } & $\begin{array}{l}\text { Before } \\
\text { matching }\end{array}$ & 0.094 & 0.276 & -48.300 & & -82.940 & 0.000 \\
\hline & After matching & 0.094 & 0.094 & 0.000 & 100.000 & 0.010 & 0.992 \\
\hline \multirow[t]{2}{*}{ Nonsingle } & $\begin{array}{l}\text { Before } \\
\text { matching }\end{array}$ & 0.906 & 0.724 & 48.300 & & 82.940 & 0.000 \\
\hline & After matching & 0.906 & 0.906 & 0.000 & 100.000 & -0.010 & 0.992 \\
\hline \multicolumn{8}{|l|}{ Years of current flow } \\
\hline \multirow[t]{2}{*}{10 years and below } & $\begin{array}{l}\text { Before } \\
\text { matching }\end{array}$ & 0.713 & 0.829 & -27.800 & & -49.320 & 0.000 \\
\hline & After matching & 0.713 & 0.713 & 0.000 & 100.000 & 0.010 & 0.995 \\
\hline \multirow[t]{2}{*}{ Over 10 years } & $\begin{array}{l}\text { Before } \\
\text { matching }\end{array}$ & 0.287 & 0.171 & 27.800 & & 49.320 & 0.000 \\
\hline & After matching & 0.287 & 0.287 & 0.000 & 100.000 & -0.010 & 0.995 \\
\hline \multicolumn{8}{|l|}{ Education level } \\
\hline \multirow[t]{2}{*}{ Below lower secondary } & $\begin{array}{l}\text { Before } \\
\text { matching }\end{array}$ & 0.188 & 0.099 & 25.800 & & 45.990 & 0.000 \\
\hline & After matching & 0.188 & 0.188 & 0.000 & 100.000 & 0.010 & 0.994 \\
\hline Lower secondary and post- & $\begin{array}{l}\text { Before } \\
\text { matching }\end{array}$ & 0.721 & 0.601 & 25.600 & & 44.720 & 0.000 \\
\hline & After matching & 0.721 & 0.721 & 0.000 & 100.000 & -0.010 & 0.989 \\
\hline Tertiary and above & $\begin{array}{l}\text { Before } \\
\text { matching }\end{array}$ & 0.090 & 0.300 & -55.000 & & -94.190 & 0.000 \\
\hline & After matching & 0.090 & 0.090 & 0.000 & 100.000 & 0.010 & 0.992 \\
\hline Industry & & & & & & & \\
\hline Primary industry & $\begin{array}{l}\text { Before } \\
\text { matching }\end{array}$ & 0.033 & 0.010 & 15.800 & & 28.610 & 0.000 \\
\hline & After matching & 0.033 & 0.032 & 1.000 & 93.900 & 1.310 & 0.189 \\
\hline Secondary industry & $\begin{array}{l}\text { Before } \\
\text { matching }\end{array}$ & 0.115 & 0.383 & -65.400 & & -112.300 & 0.000 \\
\hline & After matching & 0.115 & 0.115 & 0.000 & 100.000 & 0.030 & 0.977 \\
\hline
\end{tabular}


TABLE 5: Continued.

\begin{tabular}{|c|c|c|c|c|c|c|c|}
\hline \multirow[b]{2}{*}{ Variables } & \multirow[b]{2}{*}{ Sample } & \multicolumn{2}{|c|}{ Variable mean } & \multirow[b]{2}{*}{$\%$ bias } & \multirow[b]{2}{*}{$\begin{array}{c}\% \text { Reduce | } \\
\text { bias } \mid\end{array}$} & \multicolumn{2}{|c|}{$t$-test } \\
\hline & & $\begin{array}{l}\text { Experimental } \\
\text { group }\end{array}$ & $\begin{array}{l}\text { Control } \\
\text { group }\end{array}$ & & & $\mathrm{t}$ & $\begin{array}{c}p>1 \\
t \mid\end{array}$ \\
\hline \multirow{2}{*}{ Tertiary industry } & $\begin{array}{c}\text { Before } \\
\text { matching }\end{array}$ & 0.852 & 0.606 & 57.500 & & 99.220 & 0.000 \\
\hline & After matching & 0.852 & 0.853 & -0.300 & 99.400 & -0.690 & 0.493 \\
\hline
\end{tabular}

TABLE 6: Test results for equilibrium conditions - Method 3.

\begin{tabular}{lccc}
\hline Sample & Pseudo $R^{2}$ & LR chi $^{2}$ & chi $^{2}$ \\
\hline Before matching & 0.197 & 33654.440 & 0.000 \\
After matching & 0.000 & 2.090 & 0.999 \\
\hline
\end{tabular}

TABLE 7: Matching of samples.

\begin{tabular}{lcc}
\hline & Common support area & Total \\
\hline Nonflexible employment group & 69,052 & 69,052 \\
Flexible employment group & 55,528 & 55,528 \\
Total & 124,580 & 124,580 \\
\hline
\end{tabular}

characteristics and nonmarket factors together contribute to the income differences between the two employment groups, while the sources of income differences are mainly explained by the individual characteristics of the practitioners. Table 10 presents the results of the Oaxaca-Blinder earnings differential decomposition for each variable. As for the breakdown, in terms of differences in characteristics, the most significant factor explaining the earnings differential between the two employment groups is educational attainment, and it explains this differential negatively, meaning that as educational attainment increases, the returns to education are lower for those in flexible employment than for those in nonflexible employment. In terms of coefficient differences, age is an important factor contributing to the higher earnings of flexibly employed workers compared to nonflexibly employed workers, but again, this difference is explained negatively, with older workers having a correspondingly longer number of years of accumulated employment and the resulting years of accumulated seniority being beneficial to nonflexibly employed workers in terms of increased earnings, but having a negative effect on flexibly employed workers, reflecting to some extent that the older worker's employment advantage in the flexible employment market is declining, to the detriment of his or her ability to earn higher incomes.

6.2. Income Differences between Flexible and Nonflexible Workers in Different Sectors. The Propensity Score Matching Method (PSM) used in this study aims to measure the difference in earnings between flexible and nonflexible workers by controlling for demographic factors such as gender, age, and educational attainment. In order to further present the sources of income differences between flexible and nonflexible workers, this study separates the "industry of work" from the matching variable in the previous section and measures the degree of income differences between flexible and nonflexible workers in different industries separately.

Following the same approach as in the previous section, this study estimated the income differences between flexible and nonflexible workers in different industries using the OLS method, and the matching method, respectively. The estimated results in Table 11 show that the income of flexible workers in the primary sector is lower than that of nonflexible workers; among the four industries measured in the secondary sector, the income of flexible workers is significantly higher than that of nonflexible workers in the remaining three industries, except for the construction industry, with the largest difference in the "electricity, coal, water, and heat production and supply management industry." In the 14 industries measured in the tertiary sector, the income of flexible workers was higher than that of nonflexible workers, with the "finance," "leasing and business services," "scientific research and technical services," "education," and "culture, sport and recreation" having the highest differences. And, given that a higher proportion of flexible employment is also in the tertiary sector, the income differential between the flexible and nonflexible employment groups is mainly within the tertiary sector, and Table 12 shows the income distribution of the two groups in the tertiary sector where the income differential is more significant. Taking as examples the three industries of "leasing and business services," "scientific research and technical services," and "education," on the one hand, along with the widespread use of the mobile Internet, big data, cloud computing, and other information technologies in recent years, people's income has become more and more diversified. At the same time, more and more traditional enterprises are facing the need for digital transformation, so there is a huge demand for outsourcing services for SMEs to provide Internet marketing and operation technologies. On the other hand, technological advances have put forward higher requirements for the diversification of talent quality, prompting the emergence of many private education institutions and online master teachers, and the gradual enrichment and diversification of teaching methods under new technological support, such as live streaming and short video teaching. Compared with traditional forms of school education, this kind of practice with low entry barriers and strong autonomy is also favoured by more and more workers. Higher profit margins in these industries have attracted more people to work in this way, thus increasing the overall income of flexible-employed workers in the industry. 
TABLE 8: Differences in earnings between flexible and nonflexible workers under different matching methods and parameters.

\begin{tabular}{|c|c|c|c|c|c|}
\hline \multirow[b]{2}{*}{ Matching method } & \multicolumn{2}{|c|}{ Sample } & \multirow[b]{2}{*}{ Parameter } & \multirow[b]{2}{*}{ ATT } & \multirow{2}{*}{$\begin{array}{c}t- \\
\text { value }\end{array}$} \\
\hline & $\begin{array}{l}\text { Control } \\
\text { group }\end{array}$ & $\begin{array}{l}\text { Experimental } \\
\text { group }\end{array}$ & & & \\
\hline \multirow{5}{*}{ Nearest neighbour matching method } & 69052 & 55526 & $k=1$ & 0.1322 & 30.83 \\
\hline & 69052 & 55526 & $k=2$ & 0.1311 & 30.47 \\
\hline & 69052 & 55526 & $k=4$ & 0.1299 & 30.16 \\
\hline & 69052 & 55526 & $k=7$ & 0.1294 & 29.99 \\
\hline & 69052 & 55526 & $k=12$ & 0.1296 & 29.99 \\
\hline \multirow{12}{*}{$\begin{array}{l}\text { Caliper matching method: Nearest-neighbour matching of } \\
\text { different caliper widths }\end{array}$} & 68713 & 55373 & $\&=0.001, K=1$ & 0.2364 & 3.08 \\
\hline & 68713 & 55373 & $\&=0.01, K=1$ & 0.2364 & 3.08 \\
\hline & 68713 & 55373 & $\&=0.1, K=1$ & 0.2364 & 3.08 \\
\hline & 68713 & 55373 & $\&=0.001, K=2$ & 0.1450 & 2.71 \\
\hline & 68713 & 55373 & $\&=0.01, K=2$ & 0.1450 & 2.71 \\
\hline & 68713 & 55373 & $\&=0.1, K=2$ & 0.1450 & 2.71 \\
\hline & 68713 & 55373 & $\&=0.001, K=7$ & 0.1361 & 4.85 \\
\hline & 68713 & 55373 & $\&=0.01, K=7$ & 0.1288 & 4.72 \\
\hline & 69052 & 55373 & $\&=0.1, K=7$ & 0.1361 & 4.85 \\
\hline & 69052 & 55373 & $\&=0.001, K=12$ & 0.1192 & 5.56 \\
\hline & 68713 & 55373 & $\&=0.01, K=12$ & 0.1204 & 5.58 \\
\hline & 68713 & 55373 & $\&=0.1, K=12$ & 0.1204 & 5.58 \\
\hline \multirow{4}{*}{ Radius (caliper) matching method } & 69052 & 55488 & $\&=0.001$ & 0.1289 & 30.32 \\
\hline & 69052 & 55527 & $\&=0.005$ & 0.1341 & 31.67 \\
\hline & 69052 & 55528 & $\&=0.01$ & 0.1296 & 30.74 \\
\hline & 69052 & 55528 & $\&=0.1$ & 0.1229 & 30.10 \\
\hline \multirow{6}{*}{ Kernel matching method } & 69052 & 55528 & $k$ (epan). bw (0.06) & 0.1301 & 31.17 \\
\hline & 69052 & 55528 & $k$ (epan). bw (0.03) & 0.1311 & 31.11 \\
\hline & 69052 & 55528 & $k$ (epan). bw $(0.01)$ & 0.1270 & 30.11 \\
\hline & 69052 & 55528 & $k$ (normal). bw & 0.1210 & 29.64 \\
\hline & 69052 & 55528 & $k$ (normal). bw & 0.1269 & 30.57 \\
\hline & 69052 & 55528 & $\begin{array}{c}k(\text { normal }) . \text { bw } \\
(0.01)\end{array}$ & 0.1286 & 30.48 \\
\hline \multirow{6}{*}{ Local linear regression matching method } & 69052 & 55528 & $k$ (epan). bw (0.06) & 0.1334 & 1.77 \\
\hline & 69052 & 55528 & $k$ (epan). bw (0.03) & 0.1334 & 1.77 \\
\hline & 69052 & 55528 & $k$ (epan). bw (0.01) & 0.1327 & 1.76 \\
\hline & 69052 & 55528 & $\begin{array}{l}k \text { (normal). bw } \\
(0.06)\end{array}$ & 0.1301 & 30.69 \\
\hline & 69052 & 55528 & $k \begin{array}{l}\text { (normal). bw } \\
(0.03)\end{array}$ & 0.1315 & 31.15 \\
\hline & 69052 & 55528 & $\begin{array}{l}k \text { (normal). bw } \\
\quad(0.01)\end{array}$ & 0.1307 & 30.99 \\
\hline \multirow{4}{*}{ Martens matching } & 69052 & 55528 & $m=k=1$ & 0.1834 & 3.69 \\
\hline & 69052 & 55528 & $m=k=2$ & 0.1503 & 3.62 \\
\hline & 69052 & 55528 & $m=k=5$ & 0.1906 & 7.29 \\
\hline & 69052 & 55528 & $m=k=7$ & 0.1345 & 6.90 \\
\hline
\end{tabular}

TABle 9: Results of the Oaxaca-Blinder income variance decomposition results.

\begin{tabular}{|c|c|c|c|c|}
\hline Total variance & \multicolumn{2}{|c|}{ Characteristic variance } & \multicolumn{2}{|c|}{ Coefficient variance } \\
\hline $\ln$ (income) variance & $\ln$ (income) variance & Percentage & ln (income) variance & Percentage \\
\hline 0.0254 & 0.0137 & 53.9 & 0.0116 & 45.7 \\
\hline
\end{tabular}

6.3. Other Factors Influencing the Difference in Income between Flexible and Nonflexible Workers. In addition to the factors affecting the difference in income levels between the two groups analyzed earlier, the employment status and the intensity of the work of the workers were also important sources of income differences. First, in terms of the composition of the employment status of flexible and nonflexible workers (see Table 2), employers and selfemployed workers in flexible employment accounted for $37.1 \%$ of the total sample, while they accounted for $83.3 \%$ of the flexible workers, and the average income of both employers and self-employed workers was higher than the 
TABLE 10: Results of the Oaxaca-Blinder income variance decomposition for each variable.

\begin{tabular}{lcc}
\hline & Interpretable component (characteristics) & Noninterpretable component (coefficient) \\
\hline Gender & 0.0185 & -0.0052 \\
Age & 0.0192 & -0.3525 \\
Years of current mobility & 0.0108 & -0.0253 \\
Marital status & 0.0195 & 0.0049 \\
Educational attainment & -0.0543 & -0.0048 \\
Constant term & 0.0000 & 0.3946 \\
Total & 0.0137 & 0.0116 \\
\hline
\end{tabular}

TABLE 11: Difference in earnings between flexible and nonflexible workers by sector.

\begin{tabular}{|c|c|c|}
\hline Industry & OLS $(\%)$ & PSM (\%) \\
\hline Agriculture, forestry, and fishing & -11.4 & -13.9 \\
\hline Mining & 6.4 & 6.6 \\
\hline Manufacturing & 14.3 & 14.2 \\
\hline Production and management of electricity, coal, water, and heat production, and supply management & 21.1 & 20.9 \\
\hline Construction & 0.7 & -0.4 \\
\hline Wholesale and retail trade & 17.7 & 13.9 \\
\hline Transportation, storage, and postal services & 15.9 & 14.2 \\
\hline Accommodation and catering & 19.6 & 17.6 \\
\hline Information transmission, software, and information technology services & 20.8 & 21.0 \\
\hline Finance & 28.4 & 19.6 \\
\hline Real estate & 14.2 & 14.1 \\
\hline Rental and business services & 31.5 & 32.1 \\
\hline Scientific research and technical services & 23.0 & 22.4 \\
\hline Residential services, repairs, and other services & 16.7 & 15.6 \\
\hline Education & 26.6 & 25.1 \\
\hline Health and social work & 2.0 & 4.1 \\
\hline Culture, sports, and recreation & 28.5 & 25.3 \\
\hline Public administration, social security, and social organizations & 10.7 & 10.6 \\
\hline International organizations & 18.8 & 0.0 \\
\hline
\end{tabular}

TABLE 12: Distribution of average monthly earnings of flexibly and nonflexibly employed persons in selected sectors of the tertiary sector.

\begin{tabular}{lccc}
\hline Selected industries in the tertiary sector & $\begin{array}{c}\text { Flexibly employed } \\
\text { persons (yuan) }\end{array}$ & $\begin{array}{c}\text { Nonflexibly employed } \\
\text { persons (yuan) }\end{array}$ & $\begin{array}{c}\text { Average general income of the } \\
\text { sample (yuan) }\end{array}$ \\
\hline Information transmission, software, and & 9037.986 & 7409.779 & 7725.605 \\
information technology services & 12354.4 & 7077.148 & 7474.23 \\
Finance industry & 8014.346 & 5180.659 & 6148.01 \\
Rental and business services & 8431.618 & 6676.768 & 6933.944 \\
Scientific research and technical services & 6723.06 & 4067.913 & 4366.695 \\
Education & 8079.412 & 5447.78 & 6215.81 \\
Culture, sports, and recreation & & \\
\hline
\end{tabular}

average income of those with a regular employer in nonflexible employment. This makes the income level of flexible workers significantly higher than that of nonflexible workers. At the same time, according to the measurements of the Society for Labour Economics in 2019, the income of platform-type flexibly employed workers is about $30 \%$ higher than the average income of urban workers on the job, and the large increase in platform-type flexibly employed workers is also an important factor in the rising income level of the flexibly employed group. Second, the statistics on weekly working hours of the two groups in Table 13 show that the weekly working hours of flexible workers are approximately 12.6 hours higher than those of nonflexibly employed workers, which is close to $24 \%$ of the weekly working hours of nonflexibly employed workers. The overall higher average income of flexibly employed workers than nonflexibly employed workers is related to the fact that they put in longer working hours, and they use higher work intensity in exchange for higher income. The standard deviation of the average number of hours worked per week for flexibly employed workers is 21.8 hours, compared to 15.5 hours for nonflexibly employed workers. The standard deviation shows that the internal variation in work intensity is greater for flexibly employed workers than for nonflexibly employed workers and their work intensity is relatively more uneven. Meanwhile, in terms of hourly earnings, the hourly earnings of the flexibly employed are generally lower than those of the nonflexibly employed; especially, the closer we 
TABLE 13: Distribution of hours worked by flexible and nonflexible workers.

\begin{tabular}{|c|c|c|c|c|c|c|}
\hline & $\begin{array}{l}\text { Average weekly hours } \\
\text { worked (hours) }\end{array}$ & $\begin{array}{c}\text { Standard } \\
\text { deviation } \\
\text { (hours) }\end{array}$ & $\begin{array}{c}\text { Standard } \\
\text { deviation } \\
\text { factor }(\%)\end{array}$ & $\begin{array}{c}0.3 \text { quartile } \\
\text { hourly } \\
\text { earnings }(\$)\end{array}$ & $\begin{array}{c}0.7 \text { quartile } \\
\text { hourly } \\
\text { earnings (\$) }\end{array}$ & $\begin{array}{c}0.9 \text { quartile } \\
\text { hourly earnings } \\
(\$)\end{array}$ \\
\hline $\begin{array}{l}\text { Flexible } \\
\text { employment }\end{array}$ & 65.2 & 21.8 & 33.4 & 10.42 & 21.79 & 41.67 \\
\hline $\begin{array}{l}\text { Nonflexible } \\
\text { employment }\end{array}$ & 52.6 & 15.5 & 29.5 & 13.61 & 23.33 & 39.67 \\
\hline
\end{tabular}

get to the lower quartile, the greater the difference between the hourly earnings of the flexibly employed and the nonflexibly employed, and only after the higher quartile of 0.9 does the hourly earnings of the flexibly employed exceed those of the nonflexibly employed. It can be seen that although the average monthly income of flexibly employed workers is higher than that of nonflexibly employed workers, the higher work intensity affects the quality of employment and job acquisition of flexibly employed workers, and the polarization and uneven development are more prominent.

\section{Conclusions}

Using the 2018 China Mobility Monitoring Data, this study estimates the income differences between flexibly and nonflexibly employed persons using the OLS method and the propensity score matching method, respectively, with the average monthly income of flexibly employed persons being $11.9 \%-23.6 \%$ higher than that of nonflexibly employed persons overall. The reason for this inconsistency with the results of existing studies is that the data used in this paper are more novel and diverse in terms of the distribution of flexible employment in the sample, and the flexible workers have expanded in the scope of the study, which is reflected in the increase in the proportion of higher income groups such as employers and self-employed workers in the structure, resulting in the average income of flexible workers already being higher than that of nonflexible workers. The income quantile distribution of the two employment groups shows that the income of flexibly employed persons is lower than that of nonflexibly employed persons when the income level is below the 0.3 quantile, and the income of flexibly employed persons is higher than that of nonflexibly employed persons when the income level is above the 0.5 quantile, and this difference widens rapidly after the 0.7 quantile. Wei and Yu (2012) [21] also pointed out through empirical research that the part of the income of flexibly employed persons that is lower than that of nonflexibly employed persons is mainly caused by income differences at the middle and lower end. The results of the Oaxaca-Blinder income decomposition show that differences in characteristics explain $53.9 \%$ of the income differences between the two groups, differences in coefficients explain $45.7 \%$, and educational attainment is the most important factor explaining the income difference between the two employment groups; while age has a significant negative effect on the income growth of flexibly employed workers, the individual characteristics of the practitioners cannot explain the entire source of income difference between flexibly and nonflexibly employed workers, and segmentation and discrimination still exist in the labour market, which is consistent with the findings of Su and Du (2016) [28]. This study finds that the income levels of flexibly employed workers in the primary sector are lower than those of nonflexibly employed workers, while the income levels of flexibly employed workers in the secondary and tertiary sectors are higher than those of nonflexibly employed workers, with the difference in income in the tertiary sector being more prominent. The high profitability of industries such as "rental and business services," "scientific research and technical services," "education," and "culture, sports and entertainment," as well as the high proportion of flexibly employed persons in tertiary employment, increase the income differential between flexibly and nonflexibly employed persons. In addition, a higher proportion of flexible workers are employers and self-employed workers, both of which have higher average incomes than nonflexible workers; and, with flexible workers working an average of 65.2 hours per week, 12.6 hours more than nonflexible workers, the hourly earnings of flexible workers are generally lower than those of nonflexible workers, who work at a higher intensity in exchange for higher earnings.

The policy implications of this study are, firstly, that in view of the changes in the scale and structure of flexible employment, the employment status of flexibly employed workers is changing, and there is a need to reassess the employment status of flexibly employed workers and the differences between them and nonflexibly employed workers in terms of income levels and welfare benefits, to clarify the extent and sources of the differences in wages and welfare benefits between the two employment groups, and to formulate targeted policy interventions. The Government should formulate targeted policy interventions, and laws and regulations for new flexible employment groups, so as to take into account the rights and interests of workers in different forms of employment, effectively bridge the differences between the groups, and promote a fair and equitable labour market environment and ensure the healthy development of flexible employment. Second, attention is paid to those flexibly employed workers whose income levels are in the 0.3 quartile. Not only are their income levels significantly lower than those of nonflexibly employed workers, they are also a vulnerable group within the flexible employment group. The distribution of the sample shows that this group is mainly in 
the low-end manufacturing and service sectors, and their education level, occupational skills, and household income levels are low. Internal constraints, such as existing human capital, physical capital, economic status and social capital of the household, and external factors, such as the household registration system and industry differences, are the main factors that affect wage income differences within the flexible employment group (He et al. 2018) [29]. Enhancing human capital becomes the key to achieving occupational mobility and increasing wage income for flexible employment groups. To this end, it is important to improve the institutional mechanism of vocational training for flexibly employed people in the new industry according to the talent needs of the labour market in the new era, to enhance the vocational skills of the disadvantaged employment groups, and to improve their ability to cope with the labour market shocks brought about by the application of new technological developments while promoting their achievement of highquality employment.

There are some shortcomings in this study. On the one hand, there is no unified classification standard and statistical standard for flexible employment in China, and the forms of their existence are becoming increasingly diverse. On the other hand, based on similar studies, this paper classifies the unexplained part of the source of income differences between flexible and nonflexible workers as nonmarket factors, and it is worth exploring whether factors other than discrimination can still be stripped out of them. If other factors still exist, they may result in an amplification of the discrimination factor, and the statistical model and the selection of variables can continue to be developed and refined in the future.

As different types of flexible employment show different development trends, especially the new employment patterns derived from the platform economy and the casual labour economy have obvious differences in labour processes and labour relations compared to traditional flexible employment, a more detailed study can be conducted in the future on the labour processes, employment quality, social security, public services, and fairness of employment for a certain type of flexible employment. At the same time, as the demand side of flexible employment, the employment and management practices of enterprises are also crucial to the development of flexible employment, and the factors of the company must be included in the research framework, regulating the employment practices of enterprises, promoting the healthy development of flexible employment, and realizing a decent employment for workers.

\section{Data Availability}

The data used to support the findings of this study are available from the corresponding author upon request.

\section{Conflicts of Interest}

The authors declare that they have no conflicts of interest with respect to the publication of this paper.

\section{Acknowledgments}

This paper was supported by the major project of the $\mathrm{Na}$ tional Social Science Foundation of China (no. 19ZDA150), and the Beijing Union University Research Project (no. XP202009).

\section{References}

[1] General Office of the State Council, Opinions of the General Office of the State Council on Supporting Flexible Employment through Multiple Channels, http://www.gov.cn/zhengce/ content/2020-07/31/content_5531613.htm, 2020.

[2] State Information Center, Report on the Development of China's Sharing Economy, https://www.ndrc.gov.cn/xxgk/jd/ wsdwhfz/202102/t20210222_1267536_ext.html, 2021.

[3] Yin, Interpretation of the Social Insurance Law of the People's Republic of China, p. 49, China Labor and Social Security Press, Beijing, China, 2010.

[4] H. Y. Liu, "Economic analysis of flexible employment formation and development in China," Population and Economy, vol. 1, pp. 36-40, 2009.

[5] H. Z. Mu, Y. Chen, and X. Chen, "Research on the incentive mechanism of insurance contributions for flexibly employed people: a perspective on the utility of expected household benefits," China Population Science, vol. 6, pp. 11-24+126, 2016.

[6] F. Z. Hu and J. H. Shao, "Promoting the development of casual labor economy and flexible employment in multiple channels," Theoretical Monthly, vol. 10, pp. 67-72, 2020.

[7] K. S. Zhang, C. H. Liu, and S. L. Ding, "A study on wage differences between formal and informal employment," China Population Science, vol. 1, pp. 83-94+128, 2018.

[8] L. Y. Zhang, "Research on the influencing factors of informal employment of urban labor force-an empirical analysis based on CGSS2015," Survey World, vol. 4, pp. 31-36, 2019.

[9] T. W. Schultz, "Capital formation by education," Journal of Political Economy, vol. 68, no. 6, pp. 571-583, 1960.

[10] D. W. Wang, F. Cai, and G. Q. Zhang, "Employment and wage determination of rural migrant labor: the importance of education and training," Economics (Quarterly), vol. 7, no. 4, pp. 1131-1148, 2008.

[11] A. S. Blinder, "Wage discrimination: reduced form and structural estimates," The Journal of Human Resources, vol. 8, no. 4, pp. 436-455, 1973.

[12] Y. S. Mao, Investment Strategies of Multinational Corporations in China, China Financial and Economic Press, Beijing, China, 2005.

[13] X. Y. Li and Z. Zhao, "Evolution of employment relations in urban labor market and influencing factors," Economic Research, vol. 47, no. 9, pp. 85-98, 2012.

[14] J. Y. Hou, Flexible Employment and Wage Differentials, Xiamen University, Xiamen, China, 2019.

[15] G. Chen and S. Hamori, "Formal and informal employment and income differentials in urban China," Journal of International Development, vol. 25, no. 7, pp. 987-1004, 2013.

[16] C. P. Green and G. D. Leeves, "Job security, financial security and worker well-being: new evidence on the effects of flexible employment," Scottish Journal of Political Economy, vol. 60, no. 2, pp. 121-138, 2013.

[17] M. de Lange, M. Gesthuizen, and M. H. Wolbers, "Consequences of flexible employment at labour market entry for early career development in The Netherlands," Economic and Industrial Democracy, vol. 35, no. 3, pp. 413-434, 2014. 
[18] S. Fátima and D. C. F. Maria, "Wage differentials within a female-dominated occupation: domestic workers in informal and flexible jobs in Portugal," International Labour Review, vol. 157, no. 1, pp. 129-152, 2018.

[19] X. B. Qu, "Wage differentials between formal and informal employment in urban China-decomposition of the income gap based on heterogeneity of informal employment," Southern Economy, vol. 4, pp. 32-42, 2012.

[20] J. X. Chang and D. F. Wang, "Wage differences between formal and informal employment in urban China," Quantitative Economic and Technical Economics Research, vol. 27, no. 9, pp. 94-106, 2010.

[21] X. H. Wei and L. Z. Yu, "An empirical study of wage differences between formal and informal employment in China's urban areas: findings based on quantile regression and decomposition," Quantitative Economics and Technical Economics Research, vol. 29, no. 1, pp. 78-90, 2012.

[22] S. L. Ding, "An empirical study of wage differentials between formal and informal employment-the perspective of quantile regression," Finance and Economics Series, vol. 4, pp. 3-10, 2017.

[23] X. J. Wang, "A study on the evolution of wage differentials between formal and informal employment in urban China-a decomposition method based on unconditional quantile regression," Financial Theory and Practice, vol. 38, no. 4, pp. 89-96, 2017.

[24] Research Group of the Institute of Labour Science of the Ministry of Labour and Social Security of China, "A study on the basic problems of flexible employment in China," Economic Research Reference, vol. 45, pp. 2-16, 2005.

[25] A. R. Bryson and D. S. Purdon, The Use of Propensity Score Matching in the Evaluation of Active Labor Market Policies, Department of Work and Pensions, London, UK, 2004.

[26] M. Caliendo and S. Kopeinig, "Some practical guidance for the implementation of propensity score matching," Journal of Economic Surveys, vol. 22, no. 1, pp. 31-72, 2008.

[27] J. Q. Guo, L. Jiang, and L. L. Lu, "A review of wage difference decomposition methods," Journal of Economics (Quarterly), vol. 10, no. 2, pp. 363-414, 2011.

[28] X. F. Su and Y. D. Du, "Human capital, social capital and employment income of mobile population-a comparative analysis based on formal employment and informal employment of mobile population," Scientific Decision Making, vol. 9, pp. 43-57, 2016.

[29] Q. He, Q. Wang, and D. S. Lai, "A study on income disparity and influence mechanism of platform-based flexible workers," Population and Economy, vol. 5, pp. 1-9, 2018. 